\title{
Análise das variáveis baropodométricas entre atletas com e sem patologias ortopédicas
}

\author{
Jacqueline R. Morandin*, Lucas A. Monezi, José Adolfo D. Nabas, Luciano A. Mercadante.
}

\section{Resumo}

Esse estudo enfatiza a necessidade da análise e comparações das variáveis computadas pelo sistema da plataforma de força, baropodômetro, obtidos a partir do protocolo de marcha repetitivo para a obtenção de dados como a curva média da força de reação do solo em atletas saudáveis e com patologias, a fim de se obter uma análise comparativa dentre eles.

Palavras-chave: Baropodometria, força de reação do solo, protocolo, normalização gráfica, atletas, patologias.

\section{Introdução}

A baropodometria é um exame que analisa diferentes posturas e movimentações de um indivíduo, a partir do mapeamento das forças aplicadas no pé pelo solo, medidas por meio de sensores de pressão, dispostos ao longo de palmilhas, plataformas ou esteiras. Estudos aplicados à marcha envolvendo estes equipamentos apontam vantagens para o uso da esteira, pela liberdade para realizar a marcha sem necessidade de fios e baterias acopladas, como no caso das palmilhas, ou de direcionar o apoio para uma plataforma, podendo modificar as características da marcha. Os artigos que utilizam esteiras apontam vários protocolos distintos quanto ao número de passadas necessários para estabilidade das variáveis coletadas. Assim, estas diferenças entre os protocolos de coleta impossibilitam a análise comparativa técnica entre os estudos, como destacado em revisões sistemáticas do assunto.

Desta forma, é indispensável a criação de protocolos padronizados que permitam as análises comparativas, bem como a robustez dos dados obtidos. São comuns estudos que quantificam assimetrias e comparam indivíduos saudáveis, patológicos, atletas, dentre outros, propiciando uma melhora na qualidade técnica, além de mostrar evidências de seu valor clínico e científico, revelando-se útil para a identificação e diagnóstico de diversas patologias.

O objetivo principal desse estudo foi propor um protocolo de marcha que estabilize as curvas médias da força de reação do solo, além de normalizar estas curvas em função do ciclo da marcha, possibilitando comparações entre indivíduos.

\section{Resultados e Discussão}

Essa pesquisa foi realizada com uma esteira de pressão, marca Amcube $\AA$ (modelo FootWork Pro Walk XXL) com dezesseis participantes, sendo onze saudáveis e cinco patológicos. A marcha foi realizada em um circuito com $16,6 \mathrm{~m}$ de comprimento, por um protocolo consistindo por 36 passagens consecutivas pelo equipamento, permitindo a manutenção da velocidade durante toda a coleta. Posteriormente, foram extraídos os dados brutos das curvas de reação do solo e desenvolvido novo software para tratamento e análise destas curvas, viabilizando as comparações.

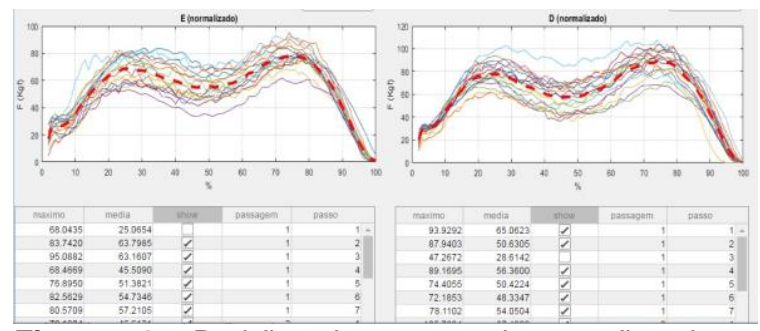

Figura 1. Padrão da curva de reação do solo (kfg), normalizada pelo ciclo da marcha (0-100\%). Destaque para a linha tracejada vermelha, que consiste na curva média, calculada para cada lado esquerdo (E) e direito (D), respectivamente.

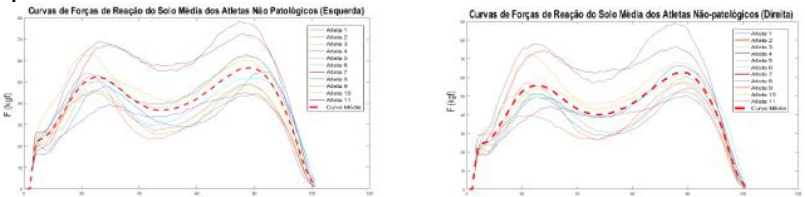

Figura 2. Curvas médias da Força de Reação do Solo de cada atleta sem patologia e curva média total (linha tracejada vermelha) em função do ciclo da marcha (Kgf e \%), sendo a direita o ciclo direito e a esquerda o ciclo esquerdo.
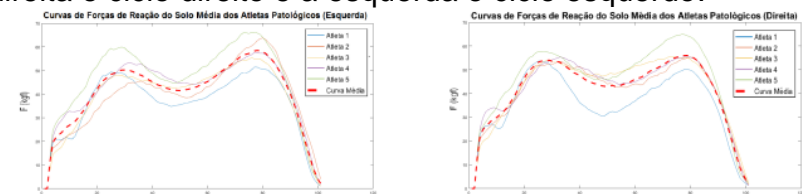

Figura 3. Curvas médias da Força de Reação do Solo de cada atleta com patologia e curva média total (linha tracejada vermelha) em função do ciclo da marcha (Kgf e \%), sendo a direita o ciclo direito e a esquerda o ciclo esquerdo.

\section{Conclusões}

Foi proposto um protocolo de coleta com 36 passagens, garantindo curvas médias com resíduos de até $1 \%$. Foi observado, também, que o padrão de curva da força de reação do solo foi equivalente entre os dois grupos, contudo, ressalta-se que é necessário um maior número de participantes com sujeitos acometidos de patologias crônicas, pois os atletas com patologias não estavam sentindo dores e não se tratando de patologias que afetariam, talvez, a marcha do atleta. Evidencia-se a possibilidade de utilizar este protocolo também para a corrida.

\section{Agradecimentos}

Ao programa CNPq/PIBIC e a Clínica Núcleo de Ortopedia, Medicina Esportiva e Reabilitação Ltda.

BULDT, A. K., Allan, J. J., Landorf, B. K., Menz, H. B. (2018). The relationship between foot posture and plantar pressure during walkingin adults: A systematic review. Gait \& Posture, 62, 56-67. 